\title{
Cultivating Agentic Teacher Identities in the Field of a Teacher Education Program
}

\author{
Lee Anne Block \\ University of Winnipeg \\ Paul Betts \\ University of Winnipeg
}

\begin{abstract}
Teacher candidates' individual and collaborative inquiry occurs within multiple and layered contexts of learning. The layered contexts support a strong connection between the practicum and the university and the emergent teaching identities. Our understanding of teacher identity is as situated and socially constructed, yet fluid and agentic. This paper explores how agentic teaching identities emerge within the layered contexts of our teacher education program as examined in five narratives of teacher candidates' experience. These narratives involve tension, inquiry, successes and risks, as teacher candidates negotiate what is means to learn how to teach, to teach and to critically reflect on knowledge needed to teach. We conclude that navigating teacher identity is a teacher candidate capacity that could be explicitly cultivated by teacher education programs.
\end{abstract}

Keywords: Teacher identities, teacher education, agency, collaboration, context

Lee Anne Block is an Associate Professor in the Faculty of Education at the University of Winnipeg. Her research and teaching are focused on how we name and engage with difference in educational locations and on cultural sustainability.

Email: 1a.block@uwinnipeg.ca

Paul Betts is an Associate Professor in the Faculty of Education at the University of Winnipeg. He developed the after-degree teacher education program described in this paper in collaboration with other faculty at the University of Winnipeg. He specializes in math education.

Email: p.betts@uwinnipeg.ca

Brock Education Journal, 25 (2), 2016 


\section{Introduction}

Teacher candidates' individual and collaborative inquiry occurs within multiple contexts of learning. Within our education program, we advocate for a co-construction of these learning contexts with teacher candidates. We value teacher candidates' agentic potential; that is, their personal and professional competency to make decisions, act on them and reflect. Thus they develop their teaching identities in response and in resistance to experiences in a teacher education program.

"How does context matter to the ways teacher candidates learn?" is a question driving the development of our program for after degree students within our Faculty of Education. These students enter the program after completing an undergraduate degree in other disciplines. Many have worked for some years before applying to Education. Their life experiences differ from education students in the Integrated Program, who commit to an education program directly from high school. The after-degree program enacts the following principles: contexts for collaborative learning among students and with educational professionals, contexts where students can engage agentically in the processes of teaching-as-inquiry, and contexts which allow for strong connections between theoretical and practical understandings of teaching. This connection between theory and practice is supported by a structured, ongoing and deliberate linking of the university and practicum school sites. This paper is focused on teacher candidates' learning embedded in the layered contexts of the program. That focus is mediated by our research question: How do agentic teaching identities emerge within the layered contexts of this program, and through the interactions of these contexts and the people within them?

\section{Theoretical Framing of Agency and Teacher Identity}

A teaching identity is complex and there are many positions on what is involved in its development, most evolving from a perspective on personal identity (Solomon, R. P., Singer, J., Campbell, A. \& Allen, A. with the assistance of Portelli, J. P., 2011 Korthagen, 2004; Britzman, D. P., 1991; Clandinin, D. J., \& Connelly, F. M. 1986). Our understanding of teacher identity is situated and socially constructed, yet fluid and agentic (Block \& Betts, 2014). Thus a teaching identity is constructed over time through the activity of teaching, as a teacher simultaneously reacts to and negotiates given contexts and human relationships at given moments (Olsen 2008, as cited in Beauchamp \& Thomas, 20 09, p.139).

Constructing a teaching identity is part of the process of teacher education, although it is often not a legislated aspect of teacher education programs (Beauchamp \& Thomas, 2009). Our position is that teacher candidates who understand their personal identities as both socially constructed and agentic will be more capable of negotiating their professional identities. Agency is something people do, not have; it is performed, acted out in individual and collective experiences (Priestley, Robinson \& Biesta, 2012) 1). A professional identity grows through practice, from doing. Teacher education programs that connect the experiences of practice with theoretical understandings can temper the tension between the two. 
Williams (2014) discusses the difficulty and value to teacher educators of negotiating identity across the university and school settings. Teacher candidates also experience multiple positions/positionings in the contexts of our program. We believe that they develop a teaching identity partially through responding to the positions these contexts offer. This development, this re-negotiation of identity, is often uncomfortable due to conflicting perspectives (Block, 2013; Boler-Zembylas, 2003) and the tension between what is known and familiar and what is learned in a professional context.

Our interest in contexts for learning emerges from our understanding of knowledge. Knowledge is considered as situated, that is, partial and emergent (Haraway, 1988); as embodied, meaning that minds and bodies interact to know (Davis, Sumara \& Luce-Kapler, 2008); and as embedded in socio-environmental contexts (Robbins and Aydede, 2009). This understanding has shaped our teacher education program as inclusive of many ways of knowing, as opposed to positioning scientific knowledge as a master narrative encoded in the exercise of declarative knowledge. The master narrative defines curriculum as a list of declarative statements. This knowledge is to be acquired by students and can be taken-up by various social processes, such as standardized testing, as something assessable and convertible into statements of accountable learning. Defining knowledge as strictly linear and declarative can result in marginalization rather than inclusion as it excludes many ways of knowing that students bring to learning, such as narrative, discovery, and inquiry.

Davis, et al. (2008) have distinguished between complicated or mechanical systems, such as a subway, and complex or organic systems, such as a society. Teacher education is identified as a complex system and, as such, it is adaptive and non-linear. A complex system encompasses more than linear understandings of declarative knowledge structures. This complex understanding of knowledge as situated, embodied and embedded produces, in part, the structures of the program. It is our intention to demonstrate how these structures result in a context where teacher candidates can notice and negotiate the tensions within their developing teaching identities. The narratives of teacher candidate experiences that follow are the source for our interpretation of how teaching identities evolve in our program.

\section{Methods}

We are interested in the experiences of our teacher candidates, as they participate in the layered contexts of the program. As such we are interested in documenting and interpreting teacher candidate's experiences of agency, as they work to develop a teaching identity. We view these experiences as complex, interconnected, intersubjective, and embedded in a socio-cultural milieu (Lincoln \& Guba, 1985). Through documenting these experiences, we can construct narratives of experience, which may illuminate the experiences of agency by the teacher candidates (Bruner, 1986). As researchers, we are well positioned to document these experiences because we are directly involved with the teacher candidates, as their university instructors and as their practicum supervisors (Maykut \& Morehouse, 1994).

We collected data from a cohort of thirty-five teacher candidates in the first year of their program. During that year, data included course work assignments and field notes of interactions with and among the teacher candidates. Coursework assignments included 
typical writing assignments as well as reflections on their teaching experiences. Field notes included synopses of debriefing meetings with teacher candidates after they taught a lesson, as well as other interactions during university course work and practicum school meetings. Also included were field notes from the other three faculty supervisors working in the after-degree program.

All data served two purposes. First, data informed our teacher-educator decisionmaking and assessment process as we taught within the program. Second, the collected data and our teaching-based analyses of data served as research data from which emerged narratives of teacher identity. These narratives deal with the beliefs, desires and commitments of teacher candidates, which are tentative and changing. We are focused on agents, and hence their agency, as people who act on their beliefs, desires and commitments (Bruner, 1990). Each narrative is embedded in the social-culture milieu of the teacher candidates' experiences, including the layered contexts of the program, which are built to occasion opportunities for collaborative professional reflection and growth. The narratives are produced through our interpretation of the field notes and sometimes include our voices as instructors/field supervisors.

In addition to the data collected in the first year of the two-year program, our ethics protocol allowed us to contact the teacher candidates for a follow-up interview after they graduated from the program. Five agreed to participate, and their interviews contribute to the data interpretations described in this paper. This one-on-one interview was conducted before they began their first teaching jobs. The interview focused on encouraging these beginning teachers to reflect on their experiences of learning to teach, as-well-as on their beliefs about effective teaching.

After interpretation of interview data and data collected in their first year of the program, we purposefully selected five narratives which represented a diversity of experiences across the cohort and illuminated our focus on agency (Creswell, 2007). This diversity reflects the variety of ways that teacher candidates can agentically develop their teaching identities in response to negotiating the layered contexts of the program. We did not seek to uncover themes across data sources. The sample of five narratives is not a representation of the different kinds of agency observed among all participants in the program. Our focus was on diverse experiences, rather than a complete or generalizable categorization of the kinds of agentic teacher identity development that could emerge from the layered contexts of the program.

\section{Enacting the Layered Contexts of the Program}

The layered contexts of the program were designed to deliberately and explicitly connect university course work and school practicum experience, commonly seen as the sites for theory and practice. Two structures are central. First is a required course in general theories of teaching and learning that legitimizes school-based professional learning meetings (PLMs) as part of that course. Second is the organization of the practicum. These structures are augmented by our orientation to collaborative learning and situated knowledge.

The hub of the program is the general course, a full-credit, two-term course, whose content is theories of teaching and learning and philosophies of schooling. The course was designed to articulate its content with practicum experiences, including a

Brock Education Journal, 25 (2), 2016 
group school-based project and individual assignments based on the practicum experience (these practicum related assignments also occur in Math and Social Studies curriculum courses in the program taught by the authors). The articulation is facilitated by the course being held in two sites, the weekly lecture at the University and the weekly seminar, termed a PLM, at the practicum school with the faculty supervisor. The valuing of situated knowledge is reflected in the physical situation of the seminars.

The weekly PLMs are constructed as spaces for learners to safely and critically examine their teaching and the teaching of others under the direction of faculty supervisors who either instruct in the program or are retired teachers. The two main qualities of professional learning communities are that they are places where participants engage in safe and critical dialogue (Darling, 2001). They must be safe so that dialogue can begin and be supported. Professional learning meetings must be critical to ensure a meaningful dialogue that moves beyond the familiar and challenges participants to reflect on theirs' and others' practices. In these PLMs, teacher candidates can examine their emerging teaching identities and professional knowledge in the contexts of the action spaces created by these communities.

The organization of the practicum is different from a traditional practicum in two significant ways. First, teacher candidates work in dyads (Bullough, et. al., 2002) during the practicum; two teacher candidates work with one cooperating teacher and her or his class over the year. Second, due to the pairing and the partnership with the school, there is a larger cohort of teacher candidates at each host school. This larger cohort forms the participants for the school-based PLMs. These structures were designed to encourage collaborative learning and to construct a context where emerging teaching identities could be negotiated with peers, in addition to professionals. In a teacher education program, the relationships or social interactions which teacher candidates experience are central. Structuring these interactions supports the development of a teaching identity grounded in collaboration and community. This collaborative process amplifies individual inquiry into teaching and opportunities for agentic experiences.

Collaborative processes within the program are supported by, and embedded in, three nested layers of learning communities. The first layer is formed by the dyads of teacher candidates and their co-operating teachers. The second layer is formed by the group of teacher candidates hosted by a given school together with their faculty supervisor, and which meet for the weekly PLMs. The third layer is formed by the full cohort of teacher candidates participating in the program and working together to complete all university course work, with opportunities to share learning experiences across the host schools. These nested layers of collaborative learning communities, dyads within school groups within the whole cohort, occasion multiple opportunities for interactions. Dyads worked together at their practicum schools on university work such as focused observations, subject-based small group teaching opportunities, and journal writing. These activities became data for reflection within the school-based PLMs and university courses. As they accumulate and interpret their teaching experiences across the university and practicum school contexts, teacher candidates construct a practice that shapes a teacher identity.

The school-based project is an example of collaboration among teacher candidates as well as the collaboration between the practicum schools and the university. At each practicum school, teacher candidates develop a school-based project, in addition to their 
practicum responsibilities in classrooms. This project is an assignment in the general teaching and learning course. For this assignment, teacher candidates are required to design and implement a grassroots extra-curricular initiative intended to address an educational need within their host school. Assessment of the project is based on a proposal to the school administration and a reflective report and presentation after the project is completed. Each project is approved by the school administration and course instructor and supported by the faculty supervisor. The project was designed for teacher candidates to experience agency. Our observations of the planning, implementation, and reflections on the projects suggest that teacher candidates did experience agency in the process of identifying an educational need through collaborating with professionals and then constructing a plan to respond to that need. Carrying out their plan and assessing it positioned the teacher candidates as professionals and supported their teacher identity (for more detail see Block \& Betts, 2013).

\section{Narratives of Agentic Teaching Identity}

Narrative 1: Engaging with the School Community. In the following narrative, the process of teacher candidates engaging with the school community and the impact on teacher identity are explored. The context of this narrative is one of the weekly professional learning meetings, where teacher candidates are working on their group project for the school, an evening event for the community they named "Family Fun Night".

In a meeting of teacher candidates and their faculty supervisor, the potential for parent participation in the Fun Night was discussed. The faculty supervisor made linkages to her experiences in that school over the previous year and to her experience in community organization. The supervisor's ability to move from the past to the present and from practicum school to community organizing theory was useful. However, the supervisor had to be careful not to contribute too much or to overtake the discussion. The teacher candidates wanted and needed to own the planning process, both temporally and spatially. That is, teacher candidates were invested in their current perceptions of the community and in their plans for their school. The place they had been located in by the student teaching office was changing; it was becoming the place where they were locating themselves as capable; as agentic (Field Note $\{\mathrm{FN}\} 2 / 10 / 12$ ).

Locating oneself, both physically and figuratively, is agentic. These teacher candidates experienced their ability to design, organize and perform a community event. In turn, they opened up the school site to the community and constructed a context within which their abilities and the abilities of community members could be demonstrated. Two months later, when presenting their project to their cohort, the teacher candidates were able to identify the tensions they had experienced in relation to trusting the community members. Their expectations had been that there would be little support or attendance from the parent community. They developed strategies for outreach and had results. After the family night, the principal told them this event had more attendance than most. Teacher candidates' understanding of the community changed as they worked through the project and experienced agency. This changed understanding of the school community, reflected changes in the teacher candidates. 
'Understand that schools are embedded in community' is an example of a declarative outcome for teacher education. As such, it can be stated in a lecture and assessed on a test. However, this process leads to an anemic understanding of this "declared" knowledge. Meaning is deepened within another context for understanding, five weeks of practicum and professional learning meeting discussions that enact and critique the connection between school and community. The statement 'Schools are embedded in community' becomes knowledge embedded in the socio-cultural experience of working with the community and this experiential learning is theorized within the university community.

Narrative 2: An Emerging Teacher Identity. The context of this narrative is presentations by teacher candidates of the school-based projects to their peers at the University near the end of the term. While presenting, one teacher candidate comes to an understanding of herself as a teacher.

One teacher candidate made a literal leap of joy concerning her accomplishments, despite difficulties experienced during the project. A teacher candidate, Yvonne (all names are pseudonyms) described the task of keeping her grade one choir students quiet for the ten minutes prior to their performance at the winter concert. She demonstrated how she had whispered in a tiny voice instructions such as "make a scary face", "make a happy face" to keep her students still and busy. In enacting that strategy and in witnessing the choir's performance, she discovered: "I am a teacher!" and she reported that to the cohort with an actual leap of recognition (FN 28/2/13). Yvonne had described how she used a "management technique" to respond to her waiting and getting-antsy choir children. Telling the story she also leaps forward (into the future) with a big smile, her understanding embodied in that moment of "I'm getting it, this thing called teaching." It was emotional, an expression of agency and also recognition of something learned, besides the declarative knowledge concerning behaviour management. Her learning included: "I can apply [declarative] knowledge acquired from elsewhere, such as the general teaching and learning course, to becoming a teacher" (Italics added by the authors). "I can learn how to be a teacher." "My identity includes being a teacher." Yvonne's learning that teaching is relational, with all its complexities, becomes embedded in the practicum experience and in the reflection on that experience created for her course. The learning is both internal and shaped with her peers.

In an earlier assigned reflection on a reading (January 22, 2013), Yvonne had written: "As I was helping my C. T. (cooperating teacher) plan her activities for her kindergarten classroom during my last practicum block, I was subconsciously using some of these ideas (Backwards Design), as we focused on the larger goals of literacy, numeracy, and social skills, before choosing specific activities to fill those needs... If I were to begin my planning by addressing the larger picture of desired knowledge, I imagine it would be at the intersection of student, teacher and curriculum." In this reflection, Yvonne is aware of the recursive nature of her learning and thereby may interrogate her understanding of how her students learn. Additionally, Yvonne can imagine herself as a teacher who considers the big picture, a broader perspective, to plan curriculum that includes interacting relationships. Yvonne's notion of knowledge includes the term "desired" and 
contextually she appears to consider herself as agentic in addressing both desired and mandated knowledge.

Narrative 3: Negotiating Tension. In the following narrative, a teacher candidate's struggle to merge different parts of his teaching identity is encountered but not resolved. The contexts of this narrative are a teacher candidate's reflections on his teaching identity at mid-term of his first year in the program and in an interview a year and a half later after graduating from the program.

I believe that my personality leads me toward perfectionism in some areas and wild creativity in other areas. I know from my experience today that I have to struggle to resist doing things for students (because they are not doing it how I would do it!) We built bridges today (suspension bridges to be more accurate!) I was very conscious of the fact that many students could not grasp the concept of a suspension bridge (despite the AWESOME model I made for the demonstration). I had to really resist the temptation to jump in when students were struggling. A few students' actually created functional suspension bridges, in the end, many did not. The real value was that for those students who were able to create a structure...they did so on their own. They learned how to do it, not just how to watch an adult do it. (Assignment, practicum reflection 12/12/12).

Turner, the teacher candidate, is conflicted about how much to help his students. He wants them to do things "right" but also values independent learning and learning by doing. Turner started and ended the program with a conviction that "Practice is way more important than theory, in general." (Post program interview, 8/28/14). When Turner was asked to consider further the import of theory for teaching, he preferred psychological to educational theory. He affirmed that doing is more important than theorizing, explaining that you can't learn to ride a bike by reading a book about it. Turner described himself as "old school" having high expectations and an essentialist agenda. However, he is interested in inquiry-based learning (which is not considered old school) and added: "I am not $100 \%$ old school" (8/24/14). Turner recognized that his approach to teaching, his "old school" teaching identity, was not aligned with the approaches of his instructors and some of the teachers in his practicum school. He experienced the tension between what is learned in a professional context and what is known and familiar. Turner's resolving of that tension is not demonstrated within the context of an assigned reflection and the context of a voluntary interview. However, the process of examining his teaching identity was also occurring in other contexts, through informal discussions with others in the cohort and professional learning meetings. How Turner integrates those experience is a function of his agency.

Narrative 4: Inquiring into Inquiry Teaching Across Sites of Learning. The following narrative illustrates how the teacher candidates' practice reflects the interaction across both the university and practicum sites. The context for this narrative is teaching an integrated unit in a practicum school during the second practicum block in spring.

Like many early years classrooms in inner city schools, Ms. Dominic's was built around carefully structured routines. The paired teacher candidates from our program, Tom, and Rose, appreciated the structures, while also occasionally resenting them. In his second practicum in spring, Tom decided to take up inquiry-based teaching as a model for this block, with the support of the resource teacher and Ms. Dominic, the cooperating teacher. At the practicum school, the 
inquiry process was a focus for professional development and was being integrated into curriculum planning in the school.

What did inquiry look like in this grade $1 / 2$ class? The faculty supervisor, Professor Block, came for an observation of a lesson led by Tom and found the class had been relocated to the art room where the students were constructing their model of the Red River in the flood. The room was full of colour, noise and focused activity as students made creative and rational decisions about their part of the model. The actual Red River can be found a ten-minute walk from the school and this spring there was a strong possibility of flooding. Tom had attended to the students concerns about a flood.

Place-based learning was a theory Tom had not yet encountered, but he identified this work as "active learning about community". As his faculty supervisor, I perceived place-based learning being enacted over the five-week practicum block. Tom had designed an inquiry-based unit integrating science and social studies and focused on the community and the potentially flooding Red River. Rose integrated math and some ELA into this design. Children cooperatively constructed a model of the river and its surrounding land and housing using modeling clay on paint roller trays (to create the river bank's slope). The students discussed how different water levels would affect the land and the buildings. They conducted experiments with melting snow and observed effects on the model's land and water. Additional science experiments on evaporation and math activities in measurement related to their topic were conducted.

An extension of this activity was a community walk to a park on the riverbank where further observations were made and connected to the model riverbank. Both Tom and Rose did an ongoing assessment to anticipate learner needs and to adapt their design in relation to those needs. Doing this inquiry with their students was a vehicle for the teacher candidates' learning about the balance between structure and flexibility. Their design and their teaching were embedded in the school culture, the school community and the school as place. (Based on Block's field notes and summative report on student teaching 29/4/13).

A reflection for his teaching portfolio, a general teaching and learning course assignment, demonstrates the connection between the practicum site and the university. Tom wrote about his math lesson, taught in his first practicum block, on odd and even numbers, which he had judged to be a failure:

Other errors I made [were] that my assignment was only curricular-centered, not child-centered. I did not consider the learning requirements of this student. Had I, I would have made a number of different sheets, rather than just one. In addition to this, I also made a poor judgment call during the lesson: I saw this student start to shut down and I did not make any quick adjustments. I failed to make any inaction decisions.

Tom is aware of the need to differentiate both in planning and while teaching. He is inquiring into his practice and how it measures up to his beliefs about teaching. We suggest he is also constructing his teaching identity as agentic; that is, he experiences himself as able to change and to make a change. Professor Block did not observe this lesson but she observed and wrote an assessment of Tom teaching another math lesson 
soon after. Professor Betts noted that: "Tom also discussed how in the previous lesson he had introduced students to odd and even numbers through an activity which was engaging but challenging. Therefore he wanted today's math class to affirm their abilities and planned accordingly. Tom has demonstrated the ability to link reflection and planning and to plan for curricular outcomes and the "living" or contextual curriculum of his classroom (formative assessment of student teaching, 13/12/12).

This cyclical inquiry into his teaching took place across the sites of university courses and the school practicum. Having a faculty supervisor who was also his professor supported Tom's inquiry across sites, as did an orientation that included emergent knowledge. Tom's conflicts about addressing the curriculum and also including the learner in his planning process did not need an immediate resolution. Tom worked at it through his teaching and his coursework. In the second practicum block, his planning and teaching evidenced a growing ability to plan differentiated learning activities and to develop curriculum in response to the teaching context. His teaching identity included the understanding that teachers (as agents) construct as well as respond to teaching contexts.

Narrative 5: Identity Shifts and the Risk of Safety. In the final narrative, teacher candidates, their cooperating teacher and the faculty supervisor are working together on how to construct safe learning communities for elementary students and, not incidentally, for teacher candidates as well.

John is a cooperating teacher in one of the practicum schools. He is adept at developing and sustaining a safe learning community (SLC). Entering this environment, teacher candidates Amanda and Nathan were able to learn to reproduce the teaching behaviours modeled by John, such as the $3 \mathrm{Rs}$ - reinforce, remind, redirect - directly connected to constructing a SLC. In this context, practice teaching became "smoother" for Nathan and Amanda than for many teacher candidates. Amanda and Nathan enjoyed their successes, seeing children respond to them in the same way as to the cooperating teacher, and witnessing learning in response to their teaching. It was a promising positive experience, but also a source of disequilibrium for Betts, the faculty advisor. His concern was that when Amanda and Nathan entered their classrooms, it might be a difficult experience. Perhaps one of the main reasons that first-year teachers experience high levels of stress and difficulty teaching is because they have learned to reproduce SLC teaching behaviours, but not establish these themselves - they have experienced sustaining, but not developing a SLC.

John and Betts met to discuss the progress of Amanda and Nathan. They agreed on the distinction between sustaining and developing a SLC. How could they design an opportunity for Amanda and Nathan to experience developing a SLC? The students had come to Amanda and Nathan with an SLC already established by the CT. Betts suggested the teacher candidates generate, develop and sustain a new routine. John saw the merit of this idea but was concerned that it might disrupt the existing SLC. Betts agreed and left it with John to think about. A solution soon presented itself. A school support teacher made her classroom available. Amanda and Nathan were about to start an inquiry unit on Ancient Egypt. It was agreed that they would teach this unit entirely in the support teacher's classroom. Thus, Amanda and Nathan had to do some work in reestablishing a SLC in a new physical location, including moving back and forth 
between classrooms, having materials available and set-up of classroom space. Betts and John agreed that a new physical location would be a sufficient but not overwhelming challenge for Amanda and Nathan given their progress as teachers, and would also simulate to some degree the experience of developing a SLC, though it would largely be a matter of transferring an existing SLC to a new physical space.

The initial experiences of Amanda and Nathan in the new classroom space were not smooth. For example, they did not fully think through classroom set-up so that student sight lines of the digital overhead display were adequate from every desk seat and the learning carpet. One event, in particular, was a difficult experience for Amanda, which eroded her sense of herself of a successful teacher candidate. In this supervised lesson, Amanda was on the learning carpet leading a brainstorm to prepare for student research during the Ancient Egypt inquiry. One child, who had a tendency to be easily excited, leading to off-task behaviour, was disrupting the brainstorming. In the regular classroom, Professor Betts had seen Amanda respond appropriately and effectively to this child. "Remind" and "redirect" responses tended to help this child choose to reduce his disruptive behaviour. In this moment, Amanda had forgotten these responses and was instead declaring the behaviour inappropriate. Her responses were not working, and her frustration increased.

In the post-lesson debrief, it was clear that Amanda had not accomplished her academic learning goals for the students because of an inadequate learning environment. Professor Betts and Amanda's debrief of the lesson started with her emotions: her confidence was at risk. Professor Betts had wanted her to translate her experiences from the old physical location to the new one. He saw this as an opportunity for Amanda to find her answers, rather than telling her what he thought could have been done differently. After ten minutes of Amanda focusing on what she thought had gone wrong, Betts thought of a scaffold: he reminded her of a previous event with the same child in the old classroom and asked her to recall how she responded. Amanda recalled her SLC teaching behaviour, as a reproduction of her cooperating teacher's SLC. Next, Professor Betts asked Amanda: What did you do today with this child in the new room? It was hard for Amanda to see the difference in her approach in the two places. Amanda did not recognize the need to develop a SLC in the new site.

Professor Betts ended the debrief with Amanda with some encouraging clarifications: She could move forward in the new room by deliberately fostering a SLC, and this would prepare her to establish a SLC in her classroom in the future. The deliberation allowed her to remind herself before starting teaching as a way to prepare for in-the-moment teaching.

By co-teaching, and reminding and encouraging each other, Amanda and Nathan slowly re-developed their repertoire of SLC teaching behaviours in the new physical space, to the point where they started observing student academic learning in the inquiry unit and lessons started to become "smoother" (Based on Betts' Field Notes, Spring 2014).

The declarative knowledge acquired by Amanda and Nathan during this process included: student sight lines must work when setting up classroom space, and the 3Rs 
(Reinforce, Remind, Redirect) can work in any physical environment. The situated knowledge is embedded in the experiences of adjusting to changes in teaching environments and a changed perception of teacher identity - moving from being a successful teacher candidate to encountering failures. In this process, the teacher candidates' understanding of the connection between the physical and relational learning environments, between the formal and social curriculum, was deepened through the experiences structured by the program.

\section{Discussion: Diverse Agentic Teaching Identities}

We value teacher candidates' agentic potential to co-construct their teaching identities while negotiating the layered contexts of the program. The structures of our program function to link the university and the practicum school. Our pedagogy is based on knowledge as situated, partial, emergent, embodied and embedded in socioenvironmental contexts. The five narratives interpreted within this paper demonstrate how teacher candidates' agentic teaching identities could emerge from the layered contexts of the program.

The first narrative illustrates that locating oneself, physically and figuratively, is agentic. The teacher candidates had assumptions about the community that were undone by the actual work with the community on the Family Fun Night. When teacher candidates experience their ability to plan and enact a school-community event, they understand their place (Gruenewald, 2003) in relation to the school community declarative knowledge is a limited part of their learning. Their learning is embedded in socio-cultural contexts, having experienced the tensions of working with each other and in the community, the teacher candidates understanding of the community changed.

In the second narrative, we encounter the teacher candidate Yvonne's literal and metaphorical leap into her teacher identity. Her learning is populated by experience using declarative knowledge, an agentic relationship with "desired" knowledge, and an emerging self-awareness of the recursive nature of her personal identity that shapes a teaching identity.

Turner's story, the third narrative, is characterized as one of tension between "old school" beliefs and his desire to enact innovative approaches as well. That tension can be experienced by teacher candidates as they navigate the complexities of learning to teach has been documented by others (e.g., Betts, 2008; Heaton \& Lampert, 1993). Turner's tension emerges from his perception that his beliefs are in conflict with the approaches of his university instructors and some of the teachers in his practicum school. The tension derives from competing values, his desire to help children "do it right", and his valuing of independent learning. His teacher identity is grounded not in theoretical knowledge but practice and learning by doing. Turner's agency is characterized as navigating, although not resolving, this tension via his learning-by-doing.

The fourth narrative demonstrates how teacher candidates' practice can reflect the interaction across university and practicum sites. It begins with Tom's simultaneous appreciation and resentment of the highly structured classroom routines of his cooperating teacher. With support from school professionals and his social studies university instructor (who is also his Faculty Supervisor, Professor Block), Tom embarked on a journey to develop an inquiry in grade $1 / 2$. For Tom, the problem is how, 
not whether, to construct a child-centered curriculum. Tom lived a teaching identity that embraced the challenges of inquiry; he experienced himself as able to change and make change - to cultivate a transformative learning milieu.

The final narrative conveys some of the intricacies of the interactions within the field of teacher education. It identifies that the cooperating teacher and the faculty supervisor want to both challenge and protect the teacher candidates during the practicum. That process mirrors how teacher candidates might choose to construct a learning environment that is safe but also leaves room for students to inquire, to take risks (Salverson, 1996). The consultations within the narrative are professional learning meetings. The general course and the practicum are bridged through such professional learning meetings. These meetings include both the formal (with the faculty supervisor and cooperating teachers at the practicum school) and the informal (discussions arising in courses and among the cohort in a variety of settings). Professional learning meetings are not simply about individual teacher candidate experiences but include the shared experiences of the teaching partners and the school group, contextualized by the participating teacher educators.

\section{Conclusion}

Discovering, maintaining and refashioning one's teaching identity is ongoing in a teaching life. In this paper's narratives, we have explored the tensions experienced by teacher candidates as they develop their teaching identities. We have also outlined how our program facilitates that process. The program has permeable boundaries that enable layered contexts. We have structured those contexts so that all participants can coconstruct their teaching identities. The co-construction of teaching identities is enhanced by the participation of some teacher educators as both professors and faculty supervisors. Their participation, like the teacher candidates', encompasses both field and university sites. The interactions between teacher candidates and teacher educators link the two contexts. As teacher candidates explore these layered contexts of the program, their ways of knowing can be stretched; their teaching identities may be experienced as agentic, as well as more flexible and responsive to the dynamic complexity of teaching.

Teaching identities, in our view, include a complex rendering of knowledge for teaching. That is, what is learned is situated, partial, emergent, and embodied. What is required is more than linking theoretical knowledge of teaching, which tends to be declarative, to practical experiences of learning to teach. Rather, facilitating agentic teaching identities allows teacher candidates to experience a deeper sense of what it means to teach. These teacher candidates' experiences of the situated and partial nature of knowledge about teaching enhance their understanding and open spaces for diverse experiences with teaching and with learning to teach.

These teaching identities emerge with some discomfort, over time, agentically, through practice and critical reflection and within nested layers of collaborative learning. Teacher candidates notice and negotiate potentials and tensions within their teaching identities. Navigating teacher identities is a teacher candidate capacity (cf. Grant, 2008) that could be explicitly cultivated by teacher education programs. As such, one of our recommendations for teacher education is a curriculum that values the capacity of teacher candidates to discover, uncover, and in some cases recover, their teaching identities. This

Brock Education Journal, 25 (2), 2016 
capacity is neither outcome based nor a product of declarative knowledge. Rather it is developed through a complex organic learning system that includes schools and the university. It is sustained by situating the structures of teacher education within a metaphor that links in complex ways the sites of learning, theory and practice. 


\section{References}

Betts, P. \& Block, L. A. (2013). Reimagining Teacher Education: Our Ongoing Story. In L. Thomas (Ed.), What is Canadian about Canadian Teacher Education? Multiple Perspectives on Canadian Teacher Education in the Twenty-First Century (pp. 402-419). Working Conference Papers 2011 e-book published by Canadian Association for Teacher Educators (CATE). Available online at https://sites.google.com/site/cssecate/fall-working-conference

Betts, P. (2008). Noticing tensions in my mathematics teacher education practice. Excelsior: Leadership in Teaching and Learning, 2(2), 65-78.

Block, L. A. (2013). Locating difference in teacher education. In-education, 19(2), 57-71.

Block, L.A. \& Betts, P. (2014). Sustaining/containing agency in an alternative teacher education program. In L. Thomas (Ed.), Becoming Teacher: Sites for teacher development in Canadian Teacher Education (pp.15-31). Canadian Association for Teacher Educators (CATE).

Beauchamp, C. \& Thomas, L. (2009). Understanding teacher identity: An overview of issues in the literature and implications for teacher education. Cambridge Journal of Education, 39(2), 175-189.

Boler, M., \& Zembylas, M. (2003). Discomforting truths: The emotional terrain of understanding difference. In P. P. Trifonas (Ed.), Pedagogies of difference: Rethinking education for social change (110-136). New York: Routledge Falmer.

Britzman, D. (1991). Practice makes practice: A critical study of learning to teach. Albany: State University of New York Press.

Bruner, J. (1990). Acts of Meaning. Cambridge, MA: Harvard.

Bruner, J. (1986). Actual Minds, Possible Worlds. Cambridge, MA: Harvard.

Bullough, R. V., Jr., Young, J., Erickson, L., Birrell, J. R., Clark, D. C., Egan, M. W., Berrie, C. F., Hales, V., \& Smith, G. (2002). Rethinking field experience: Partnership teaching versus single-placement teaching. Journal of Teacher Education, 53(1), 68-80.

Clandinin, D. J., \& Connelly, F. M. (1986). Rhythms in teaching: The narrative study of personal practical knowledge of classrooms. Teaching and teacher education, 2(4), 377-387.

Creswell, J. (2007). Qualitative Inquiry \& Research Design (2nd ed.). London: Sage.

Darling, L. F. (2001). When conceptions collide: Constructing a community of inquiry for teacher education in British Columbia. Journal of Education for Teaching, 27(1), 7-21.

Davis, B., Sumara, D., \& Luce-Kapler, R. (2008). Engaging minds: Teaching in complex times $(2$ ed.). New York: Routledge.

Grant, C. A. (2008). Teacher Capacity: Introduction to the Section. In M. Cochran-Smith, S, Feiman-Nemser, D. J. McIntyre (Eds), "Handbook of Research on Teacher

Brock Education Journal, 25 (2), 2016 